\title{
REESCRITA, DIALOGISMO E ETNOGRAFIA
}

\author{
Raquel Salek Fiad \\ Universidade Estadual de Campinas \\ Campinas, São Paulo, Brasil
}

\begin{abstract}
Resumo: Com este texto, pretendo contribuir para as discussões sobre letramento acadêmico no contexto brasileiro, trazendo reflexões sobre a reescrita de textos, com base em uma perspectiva etnográfica e dialógica. Para isso, proponho uma articulação entre uma concepção dialógica da linguagem e uma perspectiva etnográfica de análise da escrita, possibilitando um acompanhamento longitudinal das escritas no contexto acadêmico através da análise dos textos e das interações em torno dos textos. Apoio-me no conceito de "história do texto" proposto por Lillis (2008) e ensaio uma análise de um texto bem como de comentários sobre esse texto produzidos por estudantes universitários brasileiros. Palavras-chave: Reescrita. Dialogismo. História do texto. Etnografia.
\end{abstract}

\section{INTRODUÇÃO}

Os estudos sobre escrita e seu ensino, no Brasil, feitos a partir da articulação de diferentes perspectivas teóricas e metodológicas, têm enfocado diferentes objetos, tais como os textos de aprendizes, as interações em sala de aula em torno do ensino da escrita, os materiais didáticos sobre ensino de escrita, as práticas docentes, para citar alguns mais frequentes.

Mais recentemente, os estudos sobre escrita de universitários têm merecido destaque no conjunto das pesquisas brasileiras sobre escrita no contexto de ensino, em grande parte impulsionados por discussões e pesquisas desenvolvidas especialmente na última década em outros países,

Professora Titular da Universidade Estadual de Campinas (UNICAMP). PhD em Linguística pela Universidade Estadual de Nova Iorque. Email: rfiad@terra.com.br 
dada a entrada de jovens pertencentes a grupos sociais na universidade, que eram, até então, excluídos do ensino universitário. A chamada expansão do ensino superior no Brasil também colocou em destaque o desempenho escrito desses novos estudantes e trouxe desafios tanto para os docentes universitários como para os pesquisadores sobre escrita.

Nesse contexto, os estudos do Letramento Acadêmico (que detalharei em seção deste artigo) têm sido uma das bases teóricas em que pesquisas recentes feitas no Brasil estão se apoiando (cf. MARINHO, 2010; FISCHER, 2007, 2010) e têm proposto o emprego de uma metodologia de base etnográfica como complementar aos estudos sobre escrita mais voltados para as análises de base linguística.

Neste texto proponho agregar minhas reflexões sobre reescrita (tema sobre o qual venho trabalhando há algum tempo), a uma dimensão etnográfica para desenvolver uma análise no quadro dos estudos de letramento acadêmico, com base em uma concepção dialógica da linguagem. Com essas reflexões, pretendo articular teorias e metodologias da ordem dos estudos enunciativos da linguagem com estudos de base etnográfica, que serão mais detalhados no correr do texto.

Inicialmente apresento essas teorias e metodologias, propondo a articulação que vislumbro para, em seguida, ensaiar uma análise de alguns dados para ilustrar a possibilidade de articulação proposta. Finalizo o texto com algumas considerações sobre as contribuições desse tipo de análise para o que podemos chamar de uma proposta de ensino de escrita de base etnográfica e dialógica.

\section{SOBRE REESCRITA}

Para trabalhar com reescrita, assumo uma concepção de linguagem como um trabalho que acontece na interação social, porque os sujeitos vão se apropriando da linguagem ao se constituírem como locutores, junto aos seus interlocutores; a apropriação da linguagem implica um trabalho do sujeito, o que significa que há um movimento do sujeito e uma recriação da linguagem em cada situação de interação; cada interação é, por um lado, um momento novo de produção linguística; por outro lado, a linguagem 
não é criada a cada interação, daí ser possível falar em "reconstrução". Nesse trabalho de reconstrução, o sujeito seleciona os recursos linguísticos de que dispõe a partir da situação de interação em que se encontra. Desse modo, o trabalho com a linguagem acontece em todas as situações do comportamento verbal, seja em situações de produção oral ou em situações de produção escrita. $\mathrm{Na}$ escrita, o trabalho acontece talvez mais conscientemente, devido às condições de produção de grande parte dos gêneros discursivos escritos. Se pensarmos que, ao escrever algo como um relatório, por exemplo, o autor pode se deter na seleção dos tópicos, na decisão sobre a sequência dos tópicos, no que vai priorizar e no que vai deixar em segundo plano, em função do objetivo da escrita desse relatório, podemos perceber que todos esses movimentos do autor significam um trabalho, que será mais ou menos consciente, mais ou menos elaborado, dependendo dos recursos linguísticos de que dispõe e dos conhecimentos sobre a língua que tem.

A partir dessa concepção de linguagem, a escrita pode ser entendida como um processo, do qual a reescrita é parte. A essa concepção de linguagem como trabalho, podemos acrescentar outros suportes teóricos para pensarmos a escrita, suportes que vêm de diferentes áreas do conhecimento, mas que podem ser conjugados para uma análise da escrita, principalmente da escrita em processo de aquisição.

$\mathrm{O}$ primeiro deles tenta responder a perguntas do seguinte tipo: $\mathrm{O}$ que é escrever? Quais são os componentes de uma produção escrita? Como acontece a escrita? O que fazemos quando escrevemos? Para auxiliar nessa reflexão, destacamos as contribuições que os modelos psicológicos das atividades da escrita trouxeram. Esses modelos permitiram que fossem considerados os momentos da produção da escrita, a dificuldade e o tempo necessários para sua realização e, consequentemente, a importância das situações didáticas. Contribuíram também para afirmar que a escrita não é resultado de inspiração e que não há uma fórmula mágica que possibilite a sua concretização.

A segunda referência teórica que nos auxilia a entender o processamento da escrita se situa na linha das teorias da enunciação, que permitem pensar na enunciação escrita. Os estudos dos manuscritos 
literários, apoiados na linguística da enunciação, podem ser parcialmente transpostos para os textos dos alunos. Esses estudos reforçam as representações da escrita como trabalho que se conduz no tempo e também rejeitam qualquer sustentação às ideologias da inspiração e do dom. As teorias da enunciação consideram a língua como um fenômeno social, uma forma de ação, uma interação entre sujeitos. Essa concepção de língua admite que, ao falar e também ao escrever, os sujeitos constroem uma interlocução em que o trabalho com a língua está sempre presente. Desse modo, entende-se a língua não como um sistema previamente construído, do qual os sujeitos se apropriam nas diferentes situações de interação, mas como um sistema que prevê recursos linguísticos que são explorados indefinidamente nas interações. Esse entendimento de língua conduz a uma compreensão da escrita como um trabalho com a linguagem, que se dá diferentemente das situações de interação em que a língua oral predomina. Nas situações de interação pela escrita, a oportunidade de retomada e de exploração dos recursos linguísticos é muito mais frequente do que na oralidade. Isso não significa que, ao falarem, os falantes não estejam também refletindo sobre a língua. $\mathrm{O}$ que queremos enfatizar é a situação privilegiada de reflexão e retomada nos momentos de escrita.

O terceiro apoio teórico para o entendimento de como se processa a escrita vem da crítica genética, que se ocupa dos manuscritos literários, área que, nos últimos anos, vem se apoiando em teorias linguísticas da enunciação e na teoria dialógica de Bakhtin. Os manuscritos literários, ao proporcionarem um conhecimento das práticas de escrita de um autor, de sua maneira de construir seus textos, de seu estilo de escrita, também mostram que a escrita, além de revelar os conhecimentos linguísticos de quem a produziu, é também resultado de um projeto, de escolhas, de negociações. Embora, obviamente, não se possa dizer que rascunhos de aprendizes e manuscritos literários sejam o mesmo material, a metodologia de análise dos manuscritos pode ser emprestada para a análise dos textos de escolares. Os trabalhos de Fabre $(1991,1994)$ e Fabre-Cols (2002) têm apontado essa possibilidade.

Em meus trabalhos sobre reescrita tenho enfatizado uma mudança de perspectiva ao se olhar para os textos escritos, principalmente para os 
textos de aprendizes da escrita: mudar o olhar do produto para o processo de produção. Com base nos trabalhos de Fabre $(1991,1994)$ e Fabre-Cols (2002) que, por sua vez, adota uma perspectiva vinda de teorias da enunciação para analisar rascunhos de escolares, assumo a concepção de escrita como um trabalho que se conduz no tempo e a de reescrita como parte desse trabalho, que possibilita, ao analista, observar as marcas deixadas pelo escrevente e que indiciam, de algum modo, o trabalho realizado.

O interesse pela pesquisa sobre a reescrita em textos de aprendizes é relativamente recente no Brasil e ainda há muito a ser discutido sobre essa atividade presente na escrita. Em trabalhos desenvolvidos inicialmente, meu foco de atenção foi sobre as mudanças efetuadas nos textos e o quanto elas indiciavam sobre o trabalho dos sujeitos escreventes sobre o texto (cf. FIAD, 1991a, 1991b, 1993a, 1994, 1998). A partir de outra fase de minhas pesquisas em que a preocupação com a relação entre gênero discursivo e estilo foi o foco central, os episódios de reescrita foram considerados como indiciadores do conhecimento dos gêneros pelos aprendizes (cf. FIAD, 1993b, 1997). Mais recentemente, as questões de reescrita foram associadas à discussão sobre a possibilidade de considerá-la um movimento em direção à autoria, em textos de aprendizes da escrita.

\section{ARTICULANDO REESCRITA COM DIALOGISMO E ETNOGRAFIA}

No entanto, todo esse percurso de pesquisa tem analisado a reescrita, mesmo em sua dimensão enunciativa, levando em consideração prioritariamente as mudanças feitas, nos textos, pelos sujeitos escreventes. As interações em torno das reescritas têm ficado em um lugar secundário nas análises. Mesmo considerando-as como provocadoras da reescrita, as análises têm separado as interações e os textos, priorizando o olhar para os textos. Minha intenção agora é rever esse olhar e considerar, juntamente, nas análises, os enunciados escritos e orais que fazem parte do processo da escrita.

Para essa abordagem, que pretende unir o estudo do texto a uma perspectiva etnográfica, considero duas fontes teóricas importantes. Uma 
delas são os estudos bakhtinianos e a perspectiva dialógica da linguagem que trazem. A outra fonte são alguns estudos de letramento acadêmico, de base etnográfica e que têm a preocupação de realizar uma abordagem da escrita considerando os fatores de ordem enunciativa em uma perspectiva que inclui o texto e as interações em torno do texto.

A teoria em que venho me apoiando para refletir sobre a linguagem é a de Bakhtin (1992 [1952-1953]), que defende a ideia de que sempre que utilizamos a linguagem o fazemos através de gêneros do discurso. Os gêneros podem ser compreendidos, então, como enunciados produzidos na cadeia da comunicação humana: não existem isolados, mas em relação com os outros enunciados que os precedem e com os que os sucedem. Nas pesquisas desenvolvidas, o conceito de gênero do discurso tem sido fundamental por possibilitar compreender a produção da linguagem nas diferentes esferas da atividade humana em um processo dialógico.

Essa concepção de linguagem é extremamente esclarecedora para analisarmos as escritas produzidas em um processo que envolve vários enunciados, ou seja, os enunciados podem ser entendidos nessa cadeia dialógica. Relacionando essa concepção de linguagem com a concepção de escrita como um processo, é possível analisarmos os movimentos de retomada dos textos, suas continuidades, suas mudanças, como diálogos travados pelos sujeitos nas suas histórias de escrita.

Em seu artigo intitulado Students' writing as 'academic literacies': drawing on Bakhtin to move from critique to design, Lillis (2003) propõe que o dialogismo bakhtiniano possa servir como fundamento para propostas de ensino da escrita, em contraposição ao ensino monológico predominante, criticado por ela e por outros estudiosos do Letramento Acadêmico. A base dialógica inclui ter uma atitude que pressupõe diferentes sujeitos e diferentes escritas no contexto acadêmico.

A perspectiva defendida por Lillis é consoante com a perspectiva etnográfica, presente em grande parte dos estudos sobre letramento acadêmico, em que ouvir os outros - no caso sujeitos que estão no processo de inserção no contexto acadêmico - faz parte do processo de entendimento desse letramento e também de práticas inovadoras no ensino de gêneros acadêmicos. 
Ainda em relação à produção de novos gêneros no contexto acadêmico, defendo um olhar para as relações intergenéricas que estão presentes nas produções de linguagem, especialmente em situações de novos gêneros e novos contextos. A esse respeito, Corrêa (2006, p. 205) aponta que "há uma relação entre dialogismo, relações intergenéricas e análise indiciária e que essa relação pode constituir-se em proveitoso recurso metodológico para o estudo de textos escritos".

Pretendo, então, incorporar à análise da reescrita uma perspectiva etnográfica, conforme concebida por Lillis (2008). Nesse texto, a autora discute as contribuições da etnografia para estudos do letramento acadêmico, considerando três possíveis níveis em que a etnografia pode ser usada em pesquisas. O terceiro nível proposto por Lillis - em que a etnografia é mais uma teoria do que um método - abre a possibilidade de se construírem análises em que o foco seja tanto o texto (que tem sido, tradicionalmente, o foco das pesquisas sobre escrita acadêmica) como o contexto. Nessa proposta, o conceito de 'prática', vindo dos estudos do Letramento, é retomado, possibilitando que as 'conversas sobre as escritas' sejam também analisadas junto com o texto que está em processo de escrita. A tentativa é construir um modelo de análise de escrita que rompa com a dicotomia entre o texto e o contexto, que vem tradicionalmente sendo feita quando os estudos etnográficos servem apenas de "pano de fundo" para as análises que acabam sendo exclusivamente textuais.

\section{O CONTEXTO DESSA DISCUSSÃO: O LETRAMENTO ACADÊMICO}

Esta discussão se insere na discussão sobre letramento acadêmico no contexto brasileiro, pretendendo contribuir tanto para uma discussão teórica sobre práticas existentes como para novas análises possíveis a partir de práticas a serem construídas.

Meu interesse nos estudos sobre letramento acadêmico (cf. FIAD, 2011) é resultante tanto de fatores inerentes ao meu campo de atuação profissional, sendo docente universitária, inserida em contexto de letramento acadêmico e formadora de novos profissionais também inseridos nesse contexto, como derivados das pesquisas que já desenvolvi 
sobre aquisição e ensino da escrita, bem como do contato com as reflexões que vários pesquisadores vêm fazendo sobre letramento acadêmico, como Street (2011, 2009), Lillis (2003, 2008), Fischer (2011).

Os Novos Estudos de Letramentos (NLS) apontam a importância de pesquisas etnográficas preocupadas em investigar a maneira como o social, o histórico, o cultural e o cognitivo interpenetram-se, caracterizando os diferentes processos e práticas de letramentos na diversidade de grupos sociais (COLLINS; BLOT, 2003). Essa perspectiva teórica, por um lado, indica-nos como as diversas práticas de leitura e escrita presentes em nossa sociedade expressam a ineficiência de práticas estandardizadas e homogeneizantes de letramento; por outro, leva-nos a entender que algumas das práticas socioculturais de leitura e escrita ocorrem em ambientes/eventos tão específicos que não há como os sujeitos produzi-las sem que estejam inseridos nessas práticas e espaços, tanto como leitores quanto produtores dos gêneros solicitados, como é o caso dos letramentos acadêmicos.

A necessidade de estudos sobre os letramentos existentes nas esferas acadêmicas é resultante do fato de que não passamos por um processo singular de letramento situado nos espaços escolares entre a infância e a adolescência, e que nossas inserções no mundo da escrita ocorrem a partir de gêneros discursivos para os quais temos a necessidade de processos de ensino/aprendizagem mesmo depois de "letrados". Essa noção de que estamos dispostos a letramentos ao longo de nossa vida e não apenas a um único letramento que ocorreria em fases escolares implica repensarmos nossa compreensão sobre questões de ensino/aprendizagem dos gêneros também na vida acadêmica.

Marinho (2010, p. 365-366) aponta que são muitos "os trabalhos que discutem o ensino-aprendizado da leitura e da escrita no ensino fundamental e médio, no Brasil. Ao contrário, a escrita acadêmica não tem recebido a merecida atenção na universidade, seja do ponto de vista do ensino, seja como objeto de pesquisa". A partir de estudos atuais realizados nos EUA e no Reino Unido, Street (2010, p. 350) também critica a "crença fortemente sustentada [...] de que o letramento precisa ser realizado antes que os estudantes empreendam estudos de ensino superior". No Brasil, essa 
crença se reproduz, sendo necessário, no entanto, questioná-la segundo a perspectiva sociocultural enunciativa da multiplicidade de letramentos existentes em práticas reais dos meios acadêmicos.

$\mathrm{O}$ mito de que o aluno deve vir pronto para a universidade para ler e escrever deriva da visão de que letramento implicaria fundamentalmente o domínio de um conjunto de competências de leitura e escrita que os alunos têm de adquirir para depois transferi-las para outros contextos. Essa crença, no entanto, ofusca o fato de que os alunos universitários podem ter um bom domínio da língua, mas isso não os leva necessariamente a terem um bom domínio dos gêneros da esfera acadêmica, ou seja, como não existe uma fase de letramento ou um único letramento, são legítimas suas dificuldades para as práticas dos gêneros acadêmicos. Anteriormente ao ingresso acadêmico, esses sujeitos ocuparam espaços sociais e eventos de letramentos em que incidiam outras práticas sociais de leitura e escrita, isto é, outros gêneros.

\section{METODOLOGIA E DADOS}

Para discutir a articulação entre reescrita e estudos de base etnográfica com pressupostos na concepção de dialogismo, desenvolvo a análise da produção escrita de estudantes universitários.

Adoto o conceito de "história do texto" (text history) de Lillis (2008), com o objetivo de trazer para a para a discussão sobre reescrita a perspectiva da etnografia, considerando-a como teoria e não como método, possibilitando a análise longitudinal de escritas de sujeitos.

Para a breve análise deste texto, os dados são parte de um corpus constituído por textos produzidos por estudantes universitários do primeiro ano de curso de Letras de uma universidade pública, durante uma disciplina de prática de leitura e escrita cursada logo no primeiro semestre do curso.

Nessa disciplina, por mim ministrada, eram trabalhados gêneros discursivos que circulam com alguma frequência em atividades durante o curso universitário, como resenhas e resumos. Como prática durante a disciplina, os estudantes trocavam os textos entre si e escreviam 
comentários para os colegas, os quais poderiam ser respondidos ou com a reescrita do texto original ou com outros comentários.

Desse modo, foi constituído um corpus formado pelos textos que eram o objetivo da disciplina bem como pelos textos que formam os diálogos entre escreventes e seus leitores. Estou considerando, para esta análise, que o texto e as conversas sobre o texto formam o que considero "história do texto". Ressalto que me aproprio do conceito de Lillis (2008) e que considero possível atribuir a este corpus um caráter etnográfico, sabendo que essa autora trabalhou com um material diversificado, constituído basicamente de textos escritos e entrevistas com os autores dos textos. No entanto, vejo uma aproximação entre os dois tipos de materiais por propiciarem, ambos, uma discussão sobre o texto, através da entrevista ou dos comentários. Esses outros textos - que são as interações - são parte do processo da escrita e são construídos dialogicamente, seja em situações de ensino (como na disciplina por mim ministrada) seja em outras situações de escrita, como as que Lillis analisa (entre acadêmicos e revisores, por exemplo).

Desse modo, a coleta e análise dos dados usa a etnografia como teoria, conforme a concepção delineada por Lillis (2008), com o objetivo de desfazer a separação na análise entre o texto e o contexto, normalmente feita em estudos em que a etnografia é utilizada de modo complementar à análise textual.

A metodologia adotada para a análise que será realizada é ancorada no paradigma indiciário de investigação em Ciências Humanas explicitado por Ginzburg (1986 [1968]) e que tem se mostrado produtivo para as discussões associadas a estilo e gêneros. Essa metodologia tem sido adotada em trabalhos sobre aquisição da escrita e tem permitido que sejam buscados, nas escritas e nos enunciados sobre elas, marcas dos diálogos que estão sendo travados.

Completando, a metodologia adotada é compatível com a fundamentação teórica já apresentada, que compreende concepções de sujeito e linguagem em uma dinamicidade que os constitui, e os indícios são uma boa maneira de se aproximar das manifestações linguísticas assim concebidas. 


\section{ALGUMA ANÁLISE}

O material que é analisado aqui compreende a primeira produção escrita de um estudante do contexto apresentado acima (texto 1), acompanhado de três comentários sobre esse texto feitos por três colegas (textos 2, 3 e 4), seguido da resposta do estudante feita alguns dias após os comentários (texto 5) e também o último texto escrito pelo mesmo estudante ao final da disciplina, em junho (texto 6).

A situação da primeira escrita foi a seguinte: solicitei aos estudantes que escrevessem uma narrativa pessoal sobre as memórias dos primeiros dias escolares, tentando recuperar, por suas lembranças, essa entrada no universo escolar. Em seguida, os textos foram lidos por outros três colegas que comentaram os aspectos que desejassem, visando provocar uma reescrita do texto. No caso deste estudante, não houve reescrita, mas um texto justificando sua primeira escrita.

A última escrita da disciplina compreendeu uma avaliação da disciplina e foi pedido aos alunos que expusessem sua apreciação sobre as práticas de leitura e escrita desenvolvidas durante o semestre.

Como "história do texto" considero o texto inicial, seguido dos comentários e da resposta do estudante, que constituem um conjunto de enunciados relacionados dialogicamente. O texto final da disciplina é trazido para esta análise por ser mais um enunciado que responde ao que foi solicitado na primeira escrita e também por responder aos comentários dos três colegas.

Os textos 2,3 e 4 contêm enunciados que indiciam algumas críticas e estranhamento dos leitores em relação ao texto 1 . Vamos aos textos e à análise.

\section{Texto 1}

Bermuda vermelha e uma camisa branca de botão. Chamava a atenção o nome bordado no bolso da camisa. Não sabia ler mas sabia que lá estava, em letras redondas e bonitas, meu nome. "Igual o Dudu" pensava.

A escola não me trazia medo. Meu irmão já passara por isso antes. Agora ele já estava no primeiro ano, o que me causava grande admiração. Eu apenas seguia seus passos. Passos com o conga 
vermelho e as meias brancas. No ano seguinte o conga seria azul marinho...

Perderia "Os Flinstones" de manhã. Acho que era o mais triste da escola. Mas tudo bem, o joguinho de bola à tarde não seria prejudicado.

E assim passavam as primeiras experiências na escola. Dos amigos, boas lembranças; da professora, a imagem de uma boneca de porcelana do dobro do nosso tamanho. Voz doce, fez doce o início.

Chorei uma vez (bem claro na memória). Caí de queixo no chão e cortei a língua. Senti um gosto estranho, não sabia o que era. Alguém disse: "Ih, ta sangrando". Foi o beliscão. Voltei pra casa a tempo de pegar "Os Flinstones".

"Eu me chamo Edson". Era feito enorme e em pontilhado. Brincar de ligar os traços não era tarefa. No final do ano do conga azul já sabia escrever um cabeçalho inteiro e gigantesco. Com o tempo, a letra encolheu e as palavras resolveram ficar fora das linhas.

Vejamos algumas das críticas e estranhamentos:

$4^{\circ}$ parágrafo: muitas frases curtas, estilo jornalístico. Dá impressão de pouco trabalhado, de pressa. (texto 2 )

Conclusão: volta ao nome (c/o na introdução). Volta à conga (você usa o conga, masc). Mas falta concluir o texto. Você introduziu um outro tema (a letra) e não concluiu bem. (texto 2 )

$4^{\circ}$ parágrafo: Veja, você inicia o parágrafo dizendo: "E assim passava as primeiras experiências na escola". Assim como? Você agora não disse praticamente nada sobre a escola, apenas descreveu seu uniforme e a vontade de imitar seu irmão, mas o aspecto escola ainda não foi abordado, o contato com os amigos, o contato com a professora não foram bem enfocados.

$5^{\circ}$ parágrafo: Bom parágrafo, perfeito o humor do final $6^{\circ}$ parágrafo: Poderia esclarecer melhor essa passagem, ou seja de quem entra sem saber e sai sabendo como foi o aprendizado em si, difícil? Demorado? (texto 4)

Por que o "beliscão"? (texto 2)

Não entendi bem o final e o "beliscão". (texto 3) 
O texto 1 e os comentários que o seguem indicam o modo como o escrevente respondeu ao que foi solicitado como primeira escrita da disciplina. Os comentaristas sentem falta de detalhes sobre a escola, os contatos com a professora e os colegas, o aprendizado das letras. $\mathrm{O}$ texto 1 fugiu ao que era esperado e ao que praticamente todos os demais textos fizeram: narraram detalhadamente a chegada à escola, os sentimentos, as professoras, os colegas.

$\mathrm{O}$ estranhamento também se refere às opções estilísticas do escrevente, que repercutem negativamente para o comentador: muitas frases curtas, estilo jornalístico. Dá impressão de pouco trabalhado, de pressa.

Até aqui, a análise mostra uma parte da história desse texto: a resposta do escrevente à solicitação da professora e a reação dos leitores ao caminho traçado pelo escrevente, fugindo à regra. Resta vermos como o escrevente responde a essas provocações que, em princípio, conduziriam a uma reescrita do texto.

O texto 5 foi a resposta do escrevente, redigido uma semana após a escrita e os comentários:

\section{Texto 5}

Observações:

O tema é muito interessante se esse período tivesse sido bem peculiar. Isso quer dizer, ter marcas características e bem próprias. Mas no momento em que recebi o tema e a proposta de produção do texto não achei nada que se constituísse em argumento forte para o desenrolar de uma narrativa. Fugi, então, para os detalhes, tais como o uniforme ou os programas de televisão. $\mathrm{Na}$ verdade meu texto não trata (como visto) das sensações primeiras de um aprendizado, as dificuldades ou alegrias, mas foi, sim, um enfoque nos bordados de uma toalha ou, como quiser, nos bastidores da escola.

A primeira observação a ser feita é que não há reescrita do texto. $\mathrm{O}$ escrevente responde aos comentários explicando por que não desenvolveu a narrativa que era esperada: "Mas no momento em que recebi o tema e a proposta de produção do texto não achei nada que se constituísse em argumento forte para o desenrolar de uma narrativa." 
Os indícios de "fuga da narrativa" presentes no texto 1 e apontados pelos comentadores, são explicitados no texto 3, que nos traz "os bastidores" da escrita.

Seguindo a "história do texto", chegamos ao texto 6, no qual o escrevente recupera sua escrita inicial:

\section{Texto 6}

O curso de leitura e produção de textos foi com certeza bem diferente do que imaginava. Com base no nome "Produção", estava esperando um trabalho mais livre. Não se entenda esse "livre" como um sinal de desgosto ou que não se teve liberdade na escrita. O que tivemos que fazer é seguir uma proposta, seja o resumo, seja a resenha. Enganou-se o Edson que pensava que continuaria suas experiências com estilos de escrita praticadas no colégio. (É importante lembrar que o que eu fazia no colégio era algo que fugia quase que completamente do que se esperava do aluno "prévestibulando". E recebi um grande apoio por parte das professoras, o que foi o passaporte para essas experiências.)

Um fato que ilustra bem isso tudo é o que tive vontade de fazer quando recebi a primeira tarefa do curso. Deu vontade de contar uma história completamente diferente do que de fato havia acontecido. Forjar uma infância diferente. Seria mais interessante contar experiências loucas de moleque traquina na escola. Mas de certa forma era um desafio partir de um enredo banal (os meus primeiros dias na escola não foram tão diferentes do que imaginava) e, através do uso das palavras, construir um texto interessante. $E$ era exatamente isso que esperava no curso, produzir textos interessantes.

Nesse texto, o escrevente expõe seu estranhamento diante de uma situação de escrita que não correspondia às suas experiências anteriores de escrita e que eram valorizadas no contexto escolar:

Enganou-se o Edson que pensava que continuaria suas experiências com estilos de escrita praticadas no colégio. (É importante lembrar que o que eu fazia no colégio era algo que fugia quase que completamente do que se esperava do aluno "pré-vestibulando". E recebi um grande apoio por parte das professoras, o que foi o passaporte para essas experiências). 
O acompanhamento dos textos de um escrevente e dos diálogos travados com seus leitores/interlocutores vai permitindo uma análise que complementa o que nos é possível depreender através dos indícios deixados nos textos, como já realizamos em análises anteriores. As interações em torno dos textos, que podem provocar ou não a reescrita ou outras réplicas por parte dos escreventes, fazem parte do ato de escrever e podem ser analisadas conjuntamente com os textos centrais nesse processo.

Não queremos dizer com isso que, através dos enunciados - o texto e os diálogos sobre o texto -, o processo da escrita fica desvendado para o analista. A intenção é olhar tanto para o texto como para os diálogos sobre o texto entendendo que há muito que não é dito em nenhum momento e que também é constitutivo do processo da escrita.

No entanto, especialmente nas situações de aprendizagem da escrita, uma análise da escrita que envolva não só o texto, mas também a história desse texto, deve contribuir para uma melhor compreensão do processo e para a proposta de situações didáticas que possibilitem a explicitação de diálogos possíveis entre os escreventes e seus leitores.

\section{CONSIDERAÇÕES FINAIS}

Os estudos de Letramento Acadêmico têm tido uma contrapartida pedagógica por constituírem uma base teórica para propostas de ensino no contexto universitário (cf. WINGATE, 2012). A grande contribuição desses estudos para o ensino da escrita tem sido reconhecer a importância de se considerar os diferentes letramentos dos aprendizes como pontos de partida para construir propostas de ensino de escrita acadêmica. Neste texto, procurei mostrar que, no processo de escrita, também os diálogos travados entre os estudantes e seus interlocutores podem se constituir em mais uma prática a ser realizada no ensino da escrita acadêmica. 


\section{REFERÊNCIAS}

BAKHTIN, M. Os gêneros do discurso. In: . Estética da criação verbal.

São Paulo: Martins Fontes, 1992 [1952-1953]. p. 277-326.

COLLINS, J.; BLOT, R. K. Literacy and literacies: text, power and identity.

Cambridge, UK: Cambridge University Press, 2003.

CORRÊA, M. L. G. Relações intergenéricas na análise indiciária de textos escritos. Trabalhos em Linguística Aplicada, n. 45, p. 205-224, jul./dez. 2006.

FABRE, C. La linguistique génétique: une autre entrée dans la production d'écrits. Repères, n. 4,1991.

. Ce qui vaut pour un manuscrit d'écrivain vaut-il pour un brouillon d'écolier? Le Français aujourd'hui, n. 108, 1994.

FABRE-COLS, C. Réécrire à l'école et au collège. De l'analyse des brouillons à l'écriture accompagnée. Issy-les-Moulineaux: ESF éditeur, 2002.

FIAD, R, S.. Operações lingüísticas presentes na reescrita de textos. Revista Internacional de Lingua Portuguesa, AULP, n. 4, 1991a.

. A escrita como trabalho. In: MARTINS, M. H. (Org.). Questões de linguagem. São Paulo: Contexto, 1991b.

. Um estudo de variantes textuais e sua contribuição ao ensino de língua materna. Caderno de Estudos Lingüísticos, n. 24, p. 35-39, 1993a.

. Estilo e homogeneidade: análise de textos de universitários. In: SEMINÁRIOS DO GEL, 22., São Paulo, 1993, Anais... São Paulo: FFLCH/USP, 1993b. V. I, p. 180-187.

. O estudo de diferentes versões de um texto e a prática escolar. In:

SEMINÁRIOS DO GEL, 23., São Paulo, 1994. Anais... São Paulo: FFLCH/USP, 1994. V. 1, p. 360-366.

. Análise de episódios de escrita reveladores da construção de um estilo. Organon, v. 11, n. 25, p. 57-69, 1997.

. Análise de um tema em vários autores (e em várias versões). In:

SEMINÁRIOS DO GEL, 27., São José do Rio Preto, 1998. Anais... São José do Rio Preto: UNESP, 1998. p. 9-84.

. A escrita na universidade. Revista da ABRALIN, v. Eletrônico, n. Especial, p. 357-369. 2. parte, 2011.

FISCHER, A. Práticas de letramento acadêmico em um curso de Engenharia Têxtil: o caso dos relatórios e suas dimensões escondidas. Scripta, v. 16, p. 54-67, out. 2011. 
. Os usos da língua na construção de sujeitos letrados: relações entre a esfera escolar e a acadêmica. Acta Scientiarum. Language and Culture (Online), v. 2, p. 215-224, 2010.

. Letramento e movimentos interlocutivos na construção do resumo em contexto acadêmico. Revista da UNIFEBE, v. 5, p. 110-120, 2007.

GINZBURG, C. Mitti Emblemi Spie: Morfologia e Storia. Torino: Einaudi. 1968. Tradução Brasileira: Mitos Emblemas Sinais: Morfologia e História. F. Carotti (trad.). São Paulo: Companhia das Letras, 1986 [1968].

LILLIS, T. Student Writing as 'Academic Literacies': Drawing on Bakhtin to Move from Critique to Design. Language and Education, v. 17, n. 3, p. 192-207, 2003.

. Ethnography as Method, Methodology, and "Deep Theorizing": Closing the Gap Between Text and Context in Academic Writing Research. Written Communication, v. 25, n. 3, p. 353-388, July 2008.

MARINHO, M. A escrita nas práticas de letramento acadêmico. Revista Brasileira de Linguística Aplicada, v. 10, n. 2, p. 363-386, 2010.

STREET, B. Academic literacies approaches to genre? Revista Brasileira de Linguística Aplicada, v. 10, n. 2, p. 347-361, 2010.

. Literacy inequalities in theory and practice: The power to name and define. Int. J. Educ. Dev., 2011.

. "Hidden" Features of Academic Paper Writing. Working Papers in Educational Linguistics, 24/1, p. 1-17, 2009.

WINGATE, U. Using academic literacies and genre-based models for academic writing instruction: A 'literacy' journey. Journal of English for Academic Purposes 11, p. 26-37, 2012.

Recebido em: 04/06/13. Aprovado em: 27/11/13.

Title: Rewriting, dialogism and ethnography

Author: Raquel Salek Fiad

Abstract: This paper intends to contribute to academic discussions on literacy in the Brazilian context with reflections about rewriting based on dialogism and an ethnographic perspective. My intention is to articulate a dialogical perspective of language studies to an ethnographic perspective of writing analysis through longitudinal interactions around writing. Based on Lillis' (2008) concept of text history, I present a brief analysis of a text written by a college student as well as comments written by his colleagues.

Keywords: Rewriting. Dialogism. Text history. Ethnography. 
Titulo: Reescritura, dialogismo y etnografia Autor: Raquel Salek Fiad

Resumen: Con este texto, pretendo contribuir para las discusiones sobre instrucción académica en el contexto brasileño, trayendo reflexiones sobre la reescritura de textos, con base en una perspectiva etnográfica y dialógica. Para eso, propongo una articulación entre un concepto dialógico del lenguaje y una perspectiva etnográfica de análisis de la escritura, posibilitando un acompañamiento longitudinal de las escrituras en el contexto académico a través del análisis de los textos y de las interacciones en torno de los textos. Me apoyo en el concepto de "historia del texto" propuesto por Lillis (2008) y ensayo un análisis de un texto bien como de comentarios sobre ese texto producidos por estudiantes universitarios brasileños.

Palabras-clave: Reescritura. Dialogismo. Historia del texto. Etnografia. 